\title{
Main Results and Implications
}

\begin{abstract}
This chapter summarizes the main results of the book. It derives implications for policies and programs, data and research. Overall, this book offers a new understanding and analysis of the links between disability and wellbeing through the human development model and panel data. The book shows that disability needs to be considered from multiple angles including aging, gender, health, and poverty. It also suggests that disability policies are unlikely to be conducive to human development for all if they focus exclusively on changing the environment and are based on an oppressed minority group approach. This book concludes with a call for inclusion and prevention interventions as the sustainable solutions to the deprivations associated with impairments and health conditions.
\end{abstract}

Keywords Disability · Inclusion · Prevention · Washington Group · Africa

JEL II $\cdot \mathrm{I} 3 \cdot \mathrm{O} 15 \cdot \mathrm{O} 19$

This chapter summarizes the main results of this book for each of the four research questions. I then derive implications for policy, data, and further research.

S. Mitra, Disability, Health and Human Development, Palgrave Studies in Disability and International Development, DOI 10.1057/978-1-137-53638-9_7 


\subsection{Summary ANd Some Implications}

\subsubsection{How Should Disability Be Defined to Analyze and Inform Policies Related to Wellbeing?}

1. This book introduces the human development model of disability, health, and wellbeing. It is a conceptual framework developed to define disability, describe and explain health deprivations, their causes, and their consequences on wellbeing. The model is based on the capability approach of Amartya Sen and informed by the socioeconomic determinants of health. It defines disability as a deprivation in terms of functionings and/or capabilities among persons with health deprivations (impairment and/or health condition). Health deprivations and disability result from the interaction of personal factors (e.g., sex, age), structural factors (e.g., policies, social attitudes, and physical environment), and resources (e.g., assets, information). It highlights the role of conversion factors and agency in shaping health deprivations and wellbeing. It is universal in that any individual is vulnerable to health deprivations and thus is at risk of disability. It points toward the need for inclusion and prevention interventions in health and disability for human development.

The human development model is applied using panel household survey data for Ethiopia, Malawi, Tanzania, and Uganda with the Washington Group short set of questions on six functional difficulties (e.g., seeing, walking) as a measure of health deprivation. The primary focus of the empirical part of the book is descriptive given the scarcity of studies on functional difficulties and wellbeing. Some of the results did vary across countries, while at the same time some patterns emerged, and these patterns for the four countries under study are summarized below. These results dispel some myths around disability when the latter is measured through functional difficulties.

\subsubsection{What Is the Prevalence of Functional Difficulties?}

2. Functional difficulties are not rare among adults in the four countries. The prevalence of functional difficulties (moderate or severe) ranges from $11 \%$ in Malawi to $15 \%$ in Tanzania and Uganda. The prevalence of severe difficulties is under $2 \%$ in Malawi and close to $4 \%$ in Ethiopia, Malawi, and Uganda. 
These results are consistent with recent findings on prevalence (e.g., WHO-World Bank 2011; Mitra and Sambamoorthi 2014) that dispel the myths that disability is rare and affects a small minority and that disability is an issue pertinent only in the context of HICs.

3. Seeing and walking difficulties are the most common functional difficulties, followed by hearing and concentrating difficulties.

4. A strong age and socioeconomic gradient in the prevalence of functional difficulties is found. About half of individuals 65 or older report functional difficulties. Women are disproportionately more likely to experience difficulties, whatever their age group. Households in the bottom quintile of the asset or expenditure distribution are 1.5-2 times more likely to have a functional difficulty compared to households in the top quintile.

5. Very few persons with functional difficulties use assistive devices (e.g., glasses) or healthcare services that could reduce such difficulties, so some of these difficulties may be preventable. This provides suggestive evidence that poverty may cause functional difficulties, at least in part.

6. Functional difficulties are not static. For Ethiopia and Uganda, where individuals are interviewed twice about their functional difficulties, a lot of persons with functional difficulties at baseline do not report such difficulties a year or two years later, and vice versa. Functional difficulties may change overtime and are fluid. This result dispels the myth that functional difficulties are static or permanent.

7. Individuals experience various degrees of functional difficulties and deprivations. The diversity in the degree of functional difficulties is correlated with the intensity of deprivations. There is not a dichotomous state of disability vs. no disability.

The previous two results imply that we are not referring here to a well-defined minority group, contrary to common perceptions and some of the arguments under the social model and the identity politics approach of the disability rights movement. Persons with functional difficulties are a large and fluid group of people, some with intermittent or temporary difficulties. Some would likely not self-identify as having a disability and may never be connected to disabled people organizations. This point, made earlier (Shakespeare 2014), is supported by the empirical evidence in this book. It is also consistent with the point made by Fujiura (2001) that disability is an ambiguous demographic. 


\subsubsection{What Inequalities Are Associated with Functional Difficulties?}

8. There is a significant, consistent, and large association between functional difficulties and deprivations. Among adults, functional difficulties are significantly associated with deprivations in employment, morbidity, and living conditions, economic insecurity and short-term mortality. Functional difficulties are also correlated with multidimensional poverty.

9. While persons with functional difficulties are a disproportionately large share of the poor, not all persons with functional difficulties are poor. Some persons with functional difficulties do achieve levels of wellbeing comparable to persons with no difficulty. This result dispels the myth that persons with disabilities are always among the poorest of the poor. Having a functional difficulty is not synonymous with being poor but considerably increases the odds of being poor, even in the poorest countries.

These last two results indicate that in Ethiopia, Malawi, Tanzania, and Uganda, persons with functional difficulties often experience deprivations. In a context where most people are poor and where there is little in terms of a social safety net, persons with functional difficulties experience a greater breadth and depth of deprivations than persons without any difficulty. Structural and resource factors contribute to this situation, although this book could not precisely isolate the extent to which structural barriers and resource constraints contribute to deprivations and to functional difficulties.

10. The association between functional difficulties and deprivations varies depending on the trajectory of functional difficulties overtime in Ethiopia and Uganda: Persons with persistent functional difficulties are worse off than persons with a one-time self-report of functional difficulty. Several subgroups are worse off among persons with functional difficulties: older persons, older women, and persons with persistent severe functional difficulties.

11. In all four countries, individuals with functional difficulties have higher odds of mortality within the next two years, everything else held constant. There is a large and consistent association between severe functional difficulties and mortality. There is a smaller but significant association between moderate difficulties and mortality for women and adults younger than 50 . 


\subsubsection{What Are the Economic Consequences of Functional Difficulties?}

12. Having increasing functional difficulties is associated with higher odds of leaving work in Ethiopia and Uganda, especially among older adults. It provides suggestive evidence that functional difficulties are a causal factor of poverty through the work channel.

\subsection{Implications for Policies and Programs}

This book's conceptual framework and empirical findings have several policy implications.

Results on the prevalence of functional difficulties and their association with deprivations show that functional difficulties are relevant to development policy. Disability measured through functional difficulties is indeed highly correlated with deprivations and poverty, whether material or multidimensional. Although Ethiopia, Malawi, Tanzania, and Uganda have national disability policies and legislations and have ratified the CRPD, more policy work is needed to curb the stark inequalities across functional status shown in this book. Current economic systems and societies in the LICs under consideration fail to provide ways to include persons with functional difficulties.

These findings provide ammunitions to demand interventions and policies in the form of the prevention of functional difficulties and the inclusion of persons with functional difficulties. Broadly, education, social protection programs, healthcare coverage, and labor market interventions are policy areas that need to address disability for inequalities to be reduced. In the context of recent calls to 'leave no one behind' in the SDGs, this book shows some of the gaps that need to be closed: 'taking on inequality'l requires taking on disability.

The results also show that disability is a crosscutting, not a specialist, issue. The human development model and its application to four countries in Africa show that in policy and research, disability needs to be considered in policies related to aging, health, gender, and poverty.

The findings imply that disability should not be seen as a policy issue that is the luxury of high-income and aging economies.

Functional difficulties seem to be preventable, at least in part, as evidenced by very limited access to assistive devices (e.g., glasses) and healthcare services, pointing toward the need for prevention policies with 
respect to health conditions/injuries (global health, public health) and functional difficulties (assistive devices, rehabilitation).

Functional difficulties seem to cause poverty, at least via work exits. While accessing work has received attention in the disability and development field, more attention is needed with respect to retaining work following the onset of a functional difficulty.

Overall, these empirical results as well as the human development model suggest that multiple track approaches are needed including at least inclusion and prevention interventions. Disability models and policies that leave out prevention are unlikely to be conducive to human development for all. They do not cover the many people with temporary difficulties or late life onsets who may not self-identify as having a disability and are not connected to disabled people organizations. They also ignore the potential wellbeing enhancements that prevention may bring about.

Despite the recent development of social protection programs in the four countries under study, including cash transfer and public works programs, inequalities across functional difficulty status are stark. The exact impact of social protection programs related to disability needs to be assessed.

More specific policy implications need further analysis at the country level. For instance, on employment policy in the context of Ethiopia, Malawi, Tanzania, and Uganda, with a relatively low employment rate for persons with functional difficulties, one needs to find out why this is the case. It could be due to how the underlying health deprivations reduce the productivity of persons with functional difficulties for the types of jobs that are available. It could be due to a lack of access to assistive devices. It could be due to structural factors, for instance, a physically inaccessible work environment or negative attitudes in the community. Once the main causes for low employment rates are better understood, it becomes feasible to develop evidence-based programs and policies to facilitate employment. The results and data presented in this book show the need for such analysis.

\subsection{IMPLicATIONS FOR DATA}

Functional difficulty indicators need to become standard in household surveys in LMICs, as well as in the monitoring systems of NGOs and governments, to inform the development of disability-inclusive policies 
and programs. The use of the Washington Group recommended questions in surveys and monitoring systems would provide some of the necessary data for this monitoring to become feasible across countries.

A measure of functional difficulties should be included as a standard correlate in studies of poverty and economic wellbeing. It would be inconceivable not to include age or gender or marital status variables as correlates. Likewise, applied researchers should at least include a measure such as the Washington Group short set as a potential correlate of poverty. There is also a need to disaggregate poverty statistics such as the $\$ 1.90$ a day or the MPI and more broadly relevant SDG indicators of the 2030 Agenda for persons with functional difficulties.

More generally, there is a need for internationally produced disability statistics with an academic or an international organization as the scorekeeper. It may have an immense effect on development practice and debates related to disability, health and human development.

More work is needed in terms of disability measurement. For instance, recommendations on the use of the Washington Group questions focus on the group with severe functional difficulties. Analyses should try to incorporate the degree of functional difficulties through different categories or a functional score. Analyses that focus on persons experiencing severe functional difficulties leave out persons with moderate functional difficulties who are at risk of poverty.

In addition, information is lacking considerably and more data is needed on structural factors (e.g., social norms, attitudes, and physical environment) and on health deprivations (e.g., health conditions) that may lead to functional difficulties and/or deprivations. Data collection efforts that collect information on health deprivations such as the Study of Global Aging and Adult Health of WHO and on environmental factors such as the Model Disability Survey (WHO-World Bank 2015) are steps in this direction.

The LSMS data used in this book is rich and yet ripe with limitations for the purpose of this study. It focused on a small set of wellbeing dimensions, often economic in nature. For instance, it had no information on individual subjective wellbeing or on social connections.

Finally, the LSMS data used here could only follow individuals for up to two years. Because of the particularly dynamic nature of functional difficulties during adulthood and the common transitions experienced by adults, it is important to avoid a single point-in-time survey contact and incorporate functional difficulties in longitudinal datasets. 


\subsection{Further ReseArch}

This book has highlighted a number of areas where more research is needed.

The human development model needs to be developed further, and its synergies with the ICF need to be considered. It also needs to be applied with data that captures more aspects of the model, including agency and structural factors (e.g., stigma).

There are puzzles with respect to the links between mortality and functional difficulties: What interventions would prevent onsets, improve recoveries or at least delay their progression to mortality? To what extent are there 'missing persons with disabilities' ${ }^{\text {? }}$ In other words, to what extent is the excessive mortality the result of the negative treatment or neglect of persons with disabilities and how can that be stopped?

More research is necessary on dimensions of wellbeing that this study did not have data on, such as subjective wellbeing, political voice and governance, social connections, and relationships.

In addition, qualitative, mixed methods and participatory studies are required to complement the quantitative analysis in this book by trying to understand the results in their complex contexts and by listening to voices and perceptions.

More research is also needed on program or policy evaluations. Social protection programs seem to disproportionately reach persons with functional difficulties in some countries and yet do not appear to manage to do away with inequalities. Some policies and programs that some LMICs have adopted after ratifying the CRPD need to be assessed. Not all such assessments need to be quantitative and large scale in nature. For instance, Díaz Ruiz et al. (2015) do a content analysis of the intentions of a home-based care program in Chile targeted at persons with severe disabilities and find that the program is unlikely to enhance the wellbeing of this group as per the capability approach. This methodology could be used for other policies and programs and is not so resource intensive; it relies primarily on a desk review of policy documents.

Finally, this book's empirical findings were focused on deprivations. Research is needed on successful case studies. The case of Richard who accompanied us throughout Chapters 1 and 2 illustrates this point. Since contracting polio at age six, Richard has had a severe walking difficulty. Richard grew up facing countless challenges associated with poverty and disability. Yet, today, as an adult, Richard does not experience any of the 
deprivations measured in this study. If not all persons with functional difficulties are poor, and some do achieve levels of wellbeing comparable to persons with no difficulty, it seems key to understand why. Are there personal, structural, or resource factors that helped them maintain or boost their wellbeing and to what extent can these factors work for other people?

\section{Notes}

1. 'Taking on Inequality' is in reference to World Bank (2016).

2. This is in reference to 'missing women' in Sen (1990).

\section{REFERENCES}

Díaz Ruiz A., N. Sánchez Durán \& A. Palá (2015). An analysis of the intentions of a Chilean disability policy through the lens of the capability approach. Journal of Human Development and Capabilities, 6(4), 483-500.

Fujiura, G. T. (2001). Emerging trends in disability. Population Today, 29(6), 9-10.

Mitra, S., \& Sambamoorthi, U. (2014). Disability prevalence among adults: Estimates for 54 countries and progress toward a global estimate. Disability and Rebabilitation, 36, 940-947.

Sen, A. K. (1990). More than 100 million women are missing. New York Review of Books, Dec. 20th, 61-66.

Shakespeare, T. (2014). Disability rights and wrongs revisited (2nd ed.). London: Routledge Taylor \& Francis.

WHO-World Bank. (2011). World report on disability. Geneva: World Health Organization.

WHO-World Bank. (2015). Model disability survey. Geneva: World Health Organization. http://www.who.int/disabilities/data/mds/en/. Accessed 14 April 2017.

World Bank. (2016). Poverty and shared prosperity 2016: Taking on inequality. Washington, DC: World Bank. doi:10.1596/978-1-4648-0958-3.

Díaz Ruiz A., N. Sánchez Durán \& A. Palá (2015). An analysis of the intentions of a Chilean disability policy through the lens of the capability approach. Journal of Human Development and Capabilities, 6(4), 483-500. 
Open Access This chapter is licensed under the terms of the Creative Commons Attribution 4.0 International License (http://creativecommons.org/licenses/ by $/ 4.0 /$ ), which permits use, sharing, adaptation, distribution and reproduction in any medium or format, as long as you give appropriate credit to the original author(s) and the source, provide a link to the Creative Commons license and indicate if changes were made.

The images or other third party material in this chapter are included in the chapter's Creative Commons license, unless indicated otherwise in a credit line to the material. If material is not included in the chapter's Creative Commons license and your intended use is not permitted by statutory regulation or exceeds the permitted use, you will need to obtain permission directly from the copyright holder.

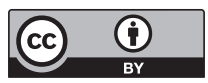

